\title{
IS GENETIC PREDISPOSITION AN IMPORTANT RISK FACTOR IN AGE-RELATED MACULAR DEGENERATION?
}

\author{
G. SILVESTRI ${ }^{1}$, P. B. JOHNSTON ${ }^{1}$ and A. E. HUGHES ${ }^{2}$ \\ Belfast
}

\begin{abstract}
SUMMARY
Age-related macular degeneration (ARMD) is the most common cause of visual morbidity in the aged in the Western world. The aetiology of ARMD is unknown. Although clinicians have noted that ARMD demonstrates a familial tendency, the question regarding the role of hereditary factors in ARMD remains unanswered. The aims of this study were to assess the level of genetic input into ARMD and to assess the mode of inheritance of the disease. Fifty affected patients and 50 age- and sexmatched controls and their immediate families were invited to take part in the study. Thirty-six patients, controls and their families were studied. Eighty-one siblings of affected patients and 78 control siblings were available. Twenty of the 81 affected siblings were found to suffer from ARMD. In contrast only 1 of 78 control siblings had ARMD. This was statistically significant. The results confirm that hereditary factors are important in the aetiology of ARMD.
\end{abstract}

Age-related macular degeneration (ARMD) remains the most common cause of registrable blindness in the elderly population of the United Kingdom. ' Projected estimates indicate that by the year 2020 as many as 7.5 million persons in the over-65 year age group may suffer from visual loss due to ARMD. ${ }^{2}$ The aetiology of ARMD remains an enigma. Clinical experience indicates that ARMD demonstrates familial clustering and that genetic factors may be important in the aetiology of this disease. One of the fundamental questions to be answered is whether ARMD is primarily a genetically determined disease which is triggered by environmental stimuli.

In 1966 Bradley $^{3}$ stated about his patients with ARMD: 'nearly every patient I have seen has had other members of the family similarly affected'. In $1973 \mathrm{Gass}^{+}$reported that $10-20 \%$ of affected individuals in his study had 'a positive family history of loss of central vision'. In 1983 Hyman et

From: 'Department of Ophthalmology and 'Department of Molecular Genetics, The Queen's University of Belfast, Belfast, Northern Ireland. Correspondence to: Miss G. Silvestri, Department of Ophthalmology, Royal Victoria Hospital, Belfast BT12 6BA, Northern Ireland. al. ${ }^{5}$ reported a 2.9-fold increased risk of ARMD if one or more family members had the condition. Recently Piguet et $a l .{ }^{6}$ investigated the relative role of heredity and the environment in ARMD by comparing the presence and characteristics of drusen in the eyes of 50 spouses and 53 sibling-pairs. Their results showed evidence of concordance of drusen between siblings but not between spouses. These findings support the belief that genetic factors may indeed have a large part to play in the pathogenesis of ARMD. The complete lack of concordance between spouses who have shared a common environment for at least 20 years suggests that environmental factors may not play a major part in the aetiology of ARMD. ${ }^{6}$ In view of the recent rapid advances in molecular genetics in many other retinal diseases we felt that even if the genetic basis of ARMD is as yet unknown, it would be important to attempt to quantify the role of genetic factors in the aetiology of this disease.

The aims of this study were to assess the level of genetic predisposition in ARMD, to calculate a 'heritability score' for ARMD and to define a mode of inheritance for the disease.

\section{PATIENTS AND METHODS}

\section{Patient Recruitment}

Fifty consecutive patients with the diagnosis of ARMD were identified from fluorescein angiography records. These were patients who had presented to the Ophthalmology Clinic within the previous 3-6 months. The Department of Ophthalmology at the Royal Victoria Hospital in Belfast is the regional centre for fluorescein angiography for Northern Ireland and has a catchment area of 1.5 million. As large numbers of patients were available, it was decided that for ease of patient travel the catchment area for the patients would be limited to a 48 kilometre radius from Belfast. Both dry and exudative macular degeneration cases were included in a random fashion. It was anticipated that as the patients were being selected from those having fluorescein angiography, those with exudative ARMD might be over-represented. 
Patients were initially approached by letter and sent an information sheet which explained the nature of the proposed study and outlined the procedure. Patients were asked to consider whether the rest of the family would be willing to attend before agreeing to participate in the study. A stamped self-addressed envelope was included for ease of reply. Those who indicated a willingness to partake in the study were sent an appointment and transport was provided for those who required it.

\section{Recruitment of Control Patients}

A number of difficulties were encountered when deciding on a suitable source of age- and sex-matched controls for the index patients. As ARMD is commonly found in the general population (incidence approximately $10 \%){ }^{7}$ it was felt that selecting people from general practitioner surgeries or hospital wards might lead to many being unsuitable because of the presence of ARMD in a large number of those selected. It was also important to find control patients who were well, able, mobile and motivated to attend for a study which was completely unrelated to them and their family. It was decided that controls should be age- and sex-matched; therefore, spouses were automatically excluded as controls. It was also felt that as spouses share a common environment, this might introduce bias into the study. It was therefore decided that our pool of post-cataract patients would provide a suitable number of patients who fulfilled the following criteria: (1) age- and sex-matched, (2) usually known to be free of ARMD and (3) with a strong motivation to help in departmental research. Several authors have discussed the relationship between ARMD and cataract. It was felt that the evidence was not conclusive enough to bias the results of this study. ${ }^{8}$

One hundred and fifty age- and sex-matched controls were selected from the list of post-operative patients of one consultant surgeon. Three control patients were selected for each ARMD patient, in order to allow for nonparticipation or pre-existing ARMD. Each control patient was assigned a number from 1 to 3 for each affected patient. Each control was contacted by letter and asked to participate. Those allocated the number 1 were contacted first; if these failed to reply or were deemed unsuitable, number 2 was contacted, and then number 3. Control patients had to meet the following criteria:

1. Free of macular degeneration.

2. Free of diabetic retinopathy (which was more severe in degree than mild background retinopathy), detached retina, hypertensive retinopathy or any other ocular disease which could confuse the fundal appearance.

3. Age within one calendar year of the paired affected patient.

4. Both pupils able to be dilated.

5. Good fundus visibility in both eyes to allow the exclusion of ARMD.

\section{Recruitment of First Degree Relatives}

Once the patient and their control patient had been seen and a family pedigree documented, a letter was sent to each available parent or sibling detailing the study and the importance that they should attend for examination. Those relatives who lived outside Northern Ireland were asked to supply the name of their ophthalmologist or optician and a report was obtained directly. For those relatives who wished to participate but who were too ill or unwilling to attend the hospital, an attempt was made to see them at home.

\section{Clinical Assessment}

A standard form was prepared for ease of completeness of history taking and examination. The details obtained were as follows:

\section{A full family pedigree.}

2. Personal details: date of birth; sex; height; weight; occupation; past medical history; medication.

3. Risk factors: cigarette/tobacco smoking; alcohol consumption; dietary habits; ultraviolet light exposure; use of cling film to wrap foods.

The patients and controls underwent the following clinical examination: assessment of visual acuity for distance and near, refractive status assessment, contrast sensitivity assessment, colour vision assessment using the D15 colour test, fundal examination, fundal photography and blood pressure measurement. A $20 \mathrm{ml}$ sample of venous blood was taken for proposed DNA analysis and linkage studies.

Documentation of fundal findings was by fundus photography. Stereoscopic photographic pairs centred on the disc and macula were taken using Zeiss $30^{\circ}$ fundus camera and Kodachrome 25 film. A reflex photograph was also taken using the fundus camera to evaluate clarity of the media. The colour negatives were mounted in clear plastic sheets and numbered in preparation for grading. All available fundus photographs were graded according to the method described by Gregor et al. ${ }^{9}$ A diagnosis of ARMD was made when changes characteristic of ARMD were present and vision was reduced to 6/9 or less, and there was no other cause for the visual loss. (The definition used for the diagnosis of ARMD is that proposed by the First National Health and Nutrition Examination Survey (NHANES-1) and which is recommended by the National Eye Institute. $)^{10}$

\section{RESULTS}

Thirty-six patients, controls and their families were available for study. Detailed family pedigrees were compiled and special note was made of any person who was known to suffer or have suffered from ocular disease. The late expression of ARMD renders this disease difficult for genetic studies. The diagnosis of ARMD was therefore made by a combination of: (1) personal examination and photographic grading in available siblings, (2) reports from ophthalmologists and optometrists and (3) history of ARMD and examination of records of parents where possible. Where the diagnosis of the ocular condition was not 
Table I. Incidence of ARMD amongst parents and siblings of patients and controls

\begin{tabular}{|c|c|c|c|}
\hline \multirow[b]{2}{*}{ Family history of ARMD } & \multicolumn{3}{|c|}{$\%$ (no.) with ARMD } \\
\hline & $\begin{array}{c}\text { Cases } \\
(n=36)\end{array}$ & $\begin{array}{l}\text { Controls } \\
(n=36)\end{array}$ & Odds ratio $(95 \% . C L)$ \\
\hline $\begin{array}{l}\text { Parental history } \\
\quad \text { (males + females) }\end{array}$ & $33.3(12)$ & 0 & $25.2(1.41-4.52 .22)^{4}$ \\
\hline $\begin{array}{l}\text { Maternal history } \\
\text { (males + females) }\end{array}$ & $19.4 \quad(7)$ & 0 & $15.6(0.86-287.42)^{\circ}$ \\
\hline $\begin{array}{l}\text { Paternal history } \\
\qquad \text { (males + females) }\end{array}$ & $13.9 \quad(5)$ & 0 & $7.4(0.38-153.21)^{a}$ \\
\hline $\begin{array}{l}\text { Sibling history } \\
\qquad \begin{array}{l}n=81 \text { ( } \text { sibs of cases }) \\
n=78 \text { (sibs of control) }\end{array}\end{array}$ & $24.7(20)$ & $1.28(1)$ & $25.2(3.43-519)^{\mathrm{b}}$ \\
\hline
\end{tabular}

"In order to avoid a value for the odds ratio of infinity due to a cell value of ' 0 ', the odds ratio uses a correction of a 0.5 addition to each cell. This method has been described by Fleiss."

'Yates corrected chi-squared $=17.01, \mathrm{df}=1, p=0.00004$

Risk to a sibling of an affected individual compared with the risk to a sibling of a control patient is 19.3 times as great (CL 2.65-140.08).

known, details about the type of visual handicap were noted. Although it is difficult to be certain of the diagnosis of ARMD in those who were unavailable for examination or were deceased, the following descriptions were taken as a probable indication of ARMD:

1. 'Poor circulation at the back of the eyes.'

2. 'Inability to read or do close work due to a problem with blood vessels at the back of both eyes.'

3. 'Wear and tear in the eye'.

\section{Parental History of ARMD}

Due to the late presentation of ARMD, verification of the diagnosis in parents is always problematical. It is appreciated that the diagnosis of ARMD in parents who were deceased is questionable, although in many families the affected patients were sure that the diagnosis was correct from the description offered by their parents' ophthalmologists at the time of diagnosis. The results which involve the parents must therefore be interpreted with caution. A summary of results regarding parental, maternal, paternal and sibling history of ARMD is given in Table I. In the affected families, 12 patients had a parent who suffered from ARMD. In contrast none of the parents of the control patients were known to suffer from ARMD. This was statistically significant with an odds ratio (OR) value of 25.22 (confidence limits (CL) 1.41-452.22). Confidence limits are wide due to the small sample number. When the data are analysed separately for maternal and paternal history of ARMD, the association is no longer significant for either maternal or paternal history of ARMD

Table II. Number of siblings affected by ARMD

\begin{tabular}{lcc}
\hline & Affected patients & Control patients \\
\hline Total siblings & 81 & 78 \\
Examined personally & 44 & 33 \\
Reports obtained & 37 & 45 \\
No. of siblings with ARMD & 20 & 1 \\
\hline
\end{tabular}

Table III. Summary of ocular lesions and visual acuity in eyes of siblings of affected patients

\begin{tabular}{llll}
\hline RVA & LVA & Lesion right eye & Lesion left eye \\
\hline $6 / 60$ & $6 / 60$ & Disciform scar & Disciform scar \\
$6 / 18$ & $6 / 18$ & Drusen & GA. RPE changes \\
HM & $6 / 9$ & RPE detachment and scar & Drusen \\
CF & $6 / 36$ & Disciform scar & Disciform scar \\
$6 / 24$ & CF & RPE. Drusen & Disciform scar \\
$6 / 9$ & $6 / 12$ & Drusen. RPE changes & Drusen, RPE changes \\
$6 / 18$ & $6 / 18$ & Drusen, RPE changes & Drusen, RPE changes \\
$6 / 12$ & $6 / 9$ & Drusen, RPE changes & Drusen, RPE changes \\
PL & $6 / 9$ & Disciform scar & Drusen \\
HM & HM & Disciform scar & Disciform scar \\
$6 / 18$ & $6 / 9$ & Drusen, RPE changes & Drusen \\
$3 / 60$ & $6 / 18$ & Disciform scar & Drusen \\
HM & $3 / 60$ & Disciform scar & Disciform scar \\
$6 / 36$ & CF & Drusen. RPE detachment & Disciform scar \\
CF & $6 / 36$ & Disciform scar & RPE detachment \\
$6 / 9$ & $6 / 12$ & RPE changes & Drusen \\
$6 / 6$ & $6 / 12$ & Drusen & GA. Drusen \\
$6 / 18$ & $6 / 9$ & Drusen, RPE changes & Drusen \\
$6 / 9$ & $6 / 12$ & Drusen & Drusen, GA \\
$6 / 6$ & $6 / 24$ & Drusen & Drusen. RPE changes \\
\hline
\end{tabular}

RVA, right visual acuity: LVA, left visual acuity: HM, hand movements: CF. counting fingers: PL. perception of light: RPE, retinal pigment epithelium: GA, geographic atrophy.

\section{Sibling History of ARMD}

The presence of ARMD in the siblings was more easily verified and therefore the results are more reliable. The total number of siblings of affected cases with reliable available data was 81 . Forty-four patient siblings were seen personally. Reports were obtained for the remaining 37. Seventy-eight control siblings were available for study. Thirty-three of these were seen personally; reports were obtained for 45 . Twenty of the 81 siblings of the affected patients were diagnosed as suffering from ARMD. In contrast only 1 control sibling of 78 had findings sufficient to diagnose ARMD according to the diagnostic criteria. The data are summarised in Table II. A summary of the most relevant fundal findings in siblings of affected patients is shown in Table III. The difference in the number of siblings affected in the affected and control families was statistically significant: $\mathrm{OR}=25.2$, confidence limits 3.43-519.0 $\left(\chi^{2}=17.1, \mathrm{df}=1, p<0.00004\right.$, $\mathrm{CL}=2.7-140$ ). The confidence limits are wide due to the small sample numbers.

\section{Relative Risk of ARMD to Siblings}

Using the data from this study it was also possible to calculate the relative risk to a sibling of an affected patient as

Table IV. Number of siblings affected per family

\begin{tabular}{lc}
\hline No. of affected members per family & No. of pedigrees \\
\hline 1 & 15 \\
2 & 11 \\
3 & 8 \\
4 & 1 \\
5 & 1 \\
6 & $1^{\text {a }}$ \\
\hline
\end{tabular}

"This family was known to G.S. prior to commencing the case-control study and provided the stimulus to begin the study of genetic factors in the aetiology of ARMD. 
compared with the risk to the sibling of a control patient. The relative risk to a sibling of an affected patient is 19.3 times that of a control sibling.

\section{Examination of Family Pedigrees}

Examination of the 36 pedigrees of the affected patients in this study shows that in 12 of the families one of the parents was affected with a variable number of offspring also affected. Ten families had multiple affected siblings but no parental history of disease. Fourteen cases appeared to be sporadic. The number of siblings affected per family is shown in Table IV.

\section{DISCUSSION}

The observed positive family history of ARMD in 58.3\% of affected patients and in none of the control patients in this study supports the claims by other authors that genetic factors are important in ARMD..$^{+-6}$ However, it is important to bear in mind that the late onset and variable expressivity of the disease render exact family and genetic studies difficult. In the 21 families with a positive family history of the disease the propositus suffered from 'wet' ARMD in 14 families and 'dry' ARMD in 7 families. Therefore, if analysed separately, $56 \%$ of cases with exudative ARMD and 64\% with dry ARMD showed a positive family history.

The number of siblings affected per family varied between 1 and 6 . Examination of the 36 pedigrees in this study shows that in 12 of the families one of the parents was affected with a variable number of offspring also affected. The mode of transmission in these cases could be interpreted as being autosomal dominant. The fact that ARMD is a disease of late onset could also help explain the fact that not as many offspring are affected as might be expected. This could be due to some of the offspring not yet having reached the age of expression of the disease or to the fact that some died young. However, if only those over 65 years of age are included, the penetrance rate in these families is virtually $100 \%$.

Ten families had multiple affected siblings but no parental history of disease. In these families both parents appeared to be clinically normal with a variable number of affected children. Where the parents were of sufficient age to be classed as 'normal', this pattern of inheritance could be representative of an autosomal recessive mode of transmission. Due to the late onset of ARMD, however, ascertainment of parent status remains a problem. Some of those families where the parents lived to old age but appeared not to be affected may represent cases which were under-reported or under-diagnosed, as is sometimes the case in ARMD. ${ }^{3}$ In others, however, one or both of the parents died at a younger age and may have manifested the disease had they lived longer: i.e. these families would then be more representative of an autosomal dominant method of transmission. The male-to-male transmission demonstrated in a number of the pedigrees rules out the $\mathrm{X}$-linked mode of inheritance.

In this study the incidence of ARMD in siblings of patients compared with control siblings was highly significant $\left(\chi^{2}=17.01, p=0.00004\right)$. Verification of the disease status of siblings was possible; over $50 \%$ of these were seen personally, the remainder by the patient's ophthalmologist or optometrist. A similar number of control siblings were also examined either personally or by opticians or ophthalmologists. It was interesting to note that there was in general an under-reporting of ARMD by patients and their relatives. Some relatives with mild to moderate ARMD changes were unaware of the condition. This under-reporting is a feature also noted by Hyman et $a l .{ }^{5}$ in a similar epidemiological study of ARMD. In that particular study all relatives were assessed by external examiners. The rate of under-reporting by relatives as compared with examiners was of the order of $30 \%$. Another interesting and unexplained feature of this study is the incidence of ARMD in control siblings (1.28\%). This is much less than the population prevalence of $8.8 \%$ found in the Framingham Eye Study. ${ }^{7}$ This can only partly be explained by the fact that the controls were chosen because they were free of ARMD. If a genetic element is important in ARMD, it is to be expected that siblings of control patients without ARMD would be at a lesser risk than that of a sample of the general population. The fact that the studies were carried out in different countries with different genetic backgrounds may also be responsible in part for this difference. The above findings indicate that genetic predisposition is of great importance in the pathogenesis of ARMD and should not be overlooked.

The results were also analysed in order to assess the influence of maternal and paternal history of ARMD. This was felt to be of importance as a previous study had found maternal but not paternal history to be of statistical significance. ${ }^{5}$ This particular result had implications regarding mitochondrial transmission in ARMD. In this present study, parental history was present in $33.3 \%$ of affected cases and in none of the control cases $(\mathrm{OR}=25.2)$. Maternal history was positive in $19.4 \%$ and patients' histories in $13.9 \%$ of affected cases and in none of the controls, but the difference was not statistically significant. The results of this study do not support the theory that mitochondrial transmission is important in ARMD.

The concept of relative risk is one that is readily understandable and useful to both the clinician and the patient. From this study the estimated relative risk to a sibling of a patient with ARMD is calculated to be high: 19.3 times that of the sibling of a control patient. It is, however, likely that this represents an average figure and that the relative risk may vary in individual families depending on the degree of genetic predisposition in a particular family. The difference in the figure for relative risk to siblings in this study and that by Hyman et al., ${ }^{5}$ i.e. 19.3 versus 2.9, reflects the much lower incidence of ARMD in the control siblings in this study.

The very late expression of ARMD provides the single most substantial hindrance in studying this disease. This study has confirmed that genetic factors do indeed play an important role in the pathogenesis of ARMD. Although 
the precise mode of inheritance remains unclear, these data may support a Mendelian mode of inheritance rather than a multifactorial mode. It may be that ARMD is a truly genetic disease, in that risk is determined primarily by inheritance; however, it is possible that time and severity of onset may be modified by behaviour and exogenous factors. Although many authors have studied the effects of associated factors on ARMD, the results have shown little consistency. The only factor which consistently correlates with ARMD, apart from age, is hypermetropia. The lack of consistency in correlating ARMD with risk factors such as physiological characteristics, medical conditions, exogenous toxins and damage by ultraviolet light, may simply highlight the difficulty of assessing multiple variables in one study. Even if ARMD is primarily genetic in origin, it is worth considering that modification of lifestyle may in some way help reduce the severity of the disease. This work therefore concludes that hereditary factors are important in the aetiology of ARMD. ARMD shares many clinical and pathological features with many of the other macular dystrophies which occur in the young. Molecular studies on retinal candidate genes would therefore be an important and logical next step in the study of this disease.

Key words: Age-related macular degeneration, Genetic. Inheritance, Risk factors, Siblings.

\section{REFERENCES}

1. Aclimandos WA, Galloway NR. Blindness in the city of Nottingham (1980-1985). Eye 1988;2:431-4.

2. Pizzarello LD. The dimensions of the problem of eye disease among the elderly. Ophthalmology 1987;94: 1191-5.

3. Bradley AE. Dystrophy of the macula. Am J Ophthalmol 1966;61:1-24.

4. Gass JDM. Serous retinal pigment epithelial detachment and degeneration. Arch Ophthalmol 1973;90:206-17.

5. Hyman LG, Lilienfeld AM, Ferris FL III, Fine SL. Senile macular degeneration: a case-control study. Am J Epidemiol 1983;118:213-27.

6. Piguet B, Wells JA, Palmvang IB, Wormald R, Chisholm IH, Bird AC. Age-related Bruch's membrane change: a clinical study of the relative role of heredity and environment. $\mathrm{Br} \mathrm{J}$ Ophthalmol 1993;77:400-3.

7. Leibowitz HM, Kreuger DE, Maunder LR, et al The Framingham Eye Study Monograph. Surv Ophthalmol 1980;24 (suppl):428-57.

8. Sperduto RD, Hiller R, Seigel D. Lens opacities and senile maculopathy. Arch Ophthalmol 1981;99:1004-8.

9. Gregor A, Bird AC, Chisholm IH. Senile disciform macular degeneration in the second eye. Br J Ophthalmol 1977;61: $141-7$.

10. Goldberg J, Flowerdew E, Smith E, Brody JA, Tso MOM. Factors associated with age-related macular degeneration. Am J Epidemiol 1988;128:700-10.

11. Fleiss JL. Statistical methods for rates and proportions. New York: John Wiley, 1973:46. 